\title{
The Enlightenment of Marxist Saving Thoughts on the Revitalization of Rural Ecology in China
}

\author{
Yang Ju \\ Institute of Economy, Jinan University, Guangzhou, China \\ Email: jnuzjjy@163.com
}

How to cite this paper: Ju, Y. (2018). The Enlightenment of Marxist Saving Thoughts on the Revitalization of Rural Ecology in China. Chinese Studies, 7, 155-163. https://doi.org/10.4236/chnstd.2018.72013

Received: April 9, 2018

Accepted: May 21, 2018

Published: May 24, 2018

Copyright $\odot 2018$ by author and Scientific Research Publishing Inc. This work is licensed under the Creative Commons Attribution International License (CC BY 4.0).

http://creativecommons.org/licenses/by/4.0/

\begin{abstract}
On October 18, 2017, Comrade Jinping Xi proposed a strategy for the revitalization of villages in the report of the 19th CPC National Congress. The issue of agriculture and rural peasants is a fundamental issue related to the national economy and the people's livelihood. The issue of solving the "three rural issues" must always be regarded as a top priority for the work of the whole Party. Therefore, the strategy of rejuvenating the country is proposed. The problems to be solved in the process of revitalization of rural ecology in China are closely related to Marx's idea of economy in "Das Kapital”. From the perspective of Marx's saving ideas, this article combines the content of China's rural revitalization strategy and sums up Marx's idea of conservation, drawing an important revelation for in the Process of Revitalizing Rural Ecosystem in China.
\end{abstract}

\section{Keywords}

Das Kapital, Marx’s Saving Ideas, Rural Ecosystem, Revitalization

\section{Introduction}

On February 4, 2018, the implementation of the strategy of rural revitalization was released on the central committee of the communist party of China (CPC). It is clearly stated in the target mission that, the rural revitalization will achieve decisive progress and the basic realization of agricultural and rural modernization by 2035 . The rural ecological environment is fundamentally improved, and the beautiful and livable countryside is basically realized. Therefore, rural ecological revitalization is an important aspect of implementing the strategy of rural revitalization, and it is of great practical significance to study the rural ecological revitalization. On the theoretical level, Marx's economical thought has a strong 
guiding significance for rural ecological revitalization in China. However, the research on Marx's economic-saving thought only discusses the economy of labor time, and draws relevant conclusions about human's free and comprehensive development. Marx's saving thought not only covers the saving of labor time but also includes the saving of resources. This article is the integration of Marxist economical thought, so as to provide feasible guidance for China's rural ecological revitalization.

The article is organized as following.

First of all, Marx's idea of economy is introduced. It includes the saving of labor time, the saving of scientific and technological progress, the saving of production concentration and the saving of waste recycling.

Secondly, we summarized the main contents of rural ecological revitalization in the central No.1 document of 2018.

Finally, we will integrate the former two parts, it is concluded that: paying attention to the application of the technology, dealing with the relationship between resources and waste, paying attention to economy of scale and cooperation, promoting the comprehensive development of farmers.

\section{The Main Viewpoint of Marx's Saving Thought}

On the one hand, Marx's thought of saving is reflected in the saving of labor time. On the other hand, it mainly embodies the saving of constant capital. In chapter $\mathrm{V}$ of the third volume of capital, Marx clearly puts forward the saving of the use of constant capital. Here, the constant capital savings can be referred to as synonymous with resource conservation or saving of production conditions.

\subsection{Labor Time Saving}

The social production process is actually the consumption process of living labor and materialized resources, which can produce savings in the process of consumption. The saving of labor time mentioned here is in fact equivalent to Marx's saving of necessary labor time (Wang, 2006). Capitalists often reduce the necessary labor time in order to maximize profits. extend the remaining labor time. The reduction of the necessary labor time and the increase of surplus labor time is exactly the mode of production Marx criticized, but on the other hand, it is precisely because of the demand for the reduction of necessary labor time that capitalists pursue advanced production techniques, that is to say, certain to the extent promoted the development of productivity. However, the saving of such necessary labor time under the socialist system and the conversion of adult free time are important conditions for the overall development of man. Under the different social and economic systems, the saving of labor time brings many different effects. Under the capitalist system, the saving of necessary labor time is used to extend the surplus labor, and the necessary labor savings under the socialist system are used to extend the free time. The concrete thoughts are summarized in Table 1 (Liu, 2017). 
Table 1. Labor time savings.

\begin{tabular}{cccc}
\hline & & Labor time & \multirow{2}{*}{ Free time } \\
\cline { 2 - 3 } & Necessary labor & Surplus labor & \\
\hline Capitalism & Shorten & Extend & Absolute shortening \\
Socialism & Shorten & Shorten (Convert to necessary labor time) & Absolute extension \\
\hline
\end{tabular}

\subsection{Resource Savings Due to Technological Advancement}

The quality of production tools can have a profound effect on resource utilization. Marx pointed out: "The more precise machine parts are processed, the better the polishing, and the more oil, soap, and other materials are saved" (Marx, 2004). The backward production tools and machines have lower resource efficiency due to lower production efficiency under the same conditions, and even cause the waste of resources cannot achieve the purpose of saving. Through innovative technologies, improved production processes, and improved quality of production tools and machines can effectively improve resource utilization and achieve resource conservation. Marx also illustrated this problem with different grain grinding techniques in Italy and France. The laggards of cereal milling in Italy have caused a great deal of grain wastage during the grinding of cereals, while the French who have mastered the more advanced technology can reduce the waste of grains during the grinding of grains and increase the flour production of the same amount of grains. At the same time, the improvement of machine manufacturing will itself bring lower energy consumption to machinery and equipment. This is the saving resulting from the advancement of science and technology.

Marx also explored the significance of the leap-forward development of the natural sciences in the promotion of productivity, and also highlighted the savings brought about by the development of productive forces. The constant cost savings caused by the forward development of the industry are characterized by the fact that the increase in the profit rate of an industrial sector is due to the development of labor productivity in another industrial sector. This development of productivity ultimately comes down to the development of mental work, especially the natural sciences. In this way, we can conclude that the development of the productive forces in the industrial sector is linked to each other. The development of productivity in an industrial sector has led to the improvement of the use of resources by various departments. The progress or development of the productive forces is driven by the development of natural sciences. This kind of economy brought about by the development of productivity, the general driving force behind it is the progress of the natural sciences. The development of natural sciences and their effective transformation into productive forces are important ways to achieve resource conservation.

\subsection{Resource Savings Resulting from the Concentration of Means of Production and the Collaboration of Workers}

Concentration of means of production, Marx first used a simple example to illu- 
strate that the cost of an engine in a large plant with two central engines would not be equal to the horsepower of the engine and would not be in the same proportion as the possible range of the engine. Increase, the cost of the conveyor, is also generally the case. Second, it can save various buildings. This refers not only to real workshops but also to warehouses and so on. The same goes for fuel, lighting, and so on. The more centralized use of resources in the social sphere, the more effective use of resources can be made and waste reduced. The large-scale collective production model marked by socialization is more suitable for the development of capitalist productivity than the traditional handicraft production model for workshops and promotes resource conservation.

Marx pointed out that "the concentration of this means of production and all the savings resulting from its large-scale application are based on the premise that workers gather and cooperate, that is, the important condition of social integration of labor." That is to say, the concentration of production materials and the savings resulting from large-scale application are preconditions for the accumulation and cooperation of workers. As a combination of centralized production and socialized labor production, it is a necessary condition for resource conservation. Only the integration of means of production and socialization of labor can achieve savings in its use. This is because in the overall production process, it is the collective consumption of the overall workers, rather than a group of workers who are not linked to each other, or who, at most, only directly collaborate with each other on a small scale, in the form of points. This naturally involves another important issue, which is the decisive significance of workers' collaborative labor to resource conservation. In this regard, Marx believes that workers are an important factor in the production process. To achieve resource conservation in the production process, workers must also be taken as an important subject. The workers referred to by Marx here are not simply individual workers, but are expressed as labor. The "combined society" of workers is an organized and coordinated group of workers. The group of workers who work in a coordinated manner is the basic prerequisite for resource conservation. Moreover, Marx also believes that the personal qualities of workers have an important influence on resource conservation in the production process. No matter how the development of natural sciences and production technologies, it is ultimately necessary to combine with the workers in the front line of production. "Only by combining the experience of workers can discover and point out where to save and how to save." Therefore, the personal qualities of workers, the level of training and education have an important impact on resource conservation in the production process. Marx pointed out that to reduce the loss and waste of production materials, it is necessary to strengthen the training and education of workers.

Finally, Marx accurately summed up this form of economy as "the total worker society's combination of the savings caused by the common use of the means of production by the workers in the production process." Marx also gave this intensive the status due to the concentration and collaboration of workers. He be- 
lieves that due to the advancement of science and technology, the savings generated from the use of excreta are all based on the premise of the accumulation and cooperation of workers. Without the accumulation and cooperation of workers, all forms of economic savings cannot be realized. Obviously, Marx was in favor of resource conservation realized under the conditions of coordination between production concentration and workers. This also explains to a certain extent that production is concentrated in the cooperation of workers. This kind of production relationship embodied in large-scale collective production has a positive impact on the development of productivity. Promote and promote the role.

\subsection{Savings Due to Reuse of Excreta}

Marx first distinguished the difference between production excreta and consumption excrement. Specifically, production excrement refers to industrial or agricultural waste, and consumption excrement refers to the excretion produced by human metabolism. Of course, some of the consumables that remain after consumption also belong to the category of consumer excrement. In particular, consumption of excreta is of great importance to agriculture. The conditions for the reuse of these excreta are the production of large quantities of excrement and the improvement of machinery and advances in science and technology in large-scale labor conditions.

Subsequently, Marx uses the Thames River as an example to illustrate the significance of waste saving. If the value of such excreta cannot be realized, the 4.5 million people's excrement in London can only be excreted in the Thames, and this way of recognizing the important value of excrement causes a huge waste on the one hand, on the other hand, it has also become the culprit of environmental pollution.

From this point, Marx put forward a way of reusing the production and consumption of excrement to achieve resource conservation, and also provided a theoretical basis for the subsequent generation of recycling economy. He took the chemical industry as an example. The chemical industry has not only found new ways to use the waste of the industry, but also uses other kinds of industrial wastes, for example, converting coal tar, which was previously almost useless, into aniline fuel come in and even turn him into medicine. In other words, it is to recycle the waste generated from upstream production as the raw material used for downstream production, which is a method of fundamentally saving resources, reducing waste, and reducing pollution. This method realizes the reuse and recycling of resources and effectively makes the resources consumed and consumed by production and consumption compensated and restored. Marx fully affirmed this way of saving resources through the reuse of waste. He pointed out that "The savings resulting from the reuse of production waste should be differentiated from the savings due to the reduction of waste" (Marx, 2004). The latter is a way to directly reduce resource consumption. The former saves resources through the recycling and recycling of waste. This eliminates the 
difference between resources and so-called waste to a certain extent. This way also improves the ability to conserve resources to the latter. The waste-reducing resource-saving approach cannot reach a high level. This waste is used as a raw material to be put into the production process here, and a conservation method for useful products is created, which substantially expands the labor target and promotes the improvement of productivity.

\subsection{Summary}

Marx's idea of resource conservation is a combination of scientific and technological progress, the concentration of production and the collaboration of workers and the reuse of excrement. Scientific and technological progress, the concentration of production, and the collaboration of workers have promoted the reuse of excrement. The process of reuse is also inseparable from the progress of science and technology and the concentration of production and the collaboration of workers (Qin \& Wang, 2014).

\section{Contents of Revitalization of China's Rural Ecology}

On October 18, 2017, Comrade Jinping Xi put forward the strategy of rejuvenating villages in the report of the party's 19th National Congress. The issue of agriculture and rural peasants is a fundamental issue related to the national economy and the people's livelihood. The issue of solving the "three rural issues" must always be the top priority of the work of the whole Party and implement the strategy of revitalizing the country.

On February 4, 2018, the Central Document No. 1 of 2018 was promulgated, namely, "Opinions of the Central Committee of the Communist Party of China on Implementing the Strategy for Revitalizing the Village". On March 5, 2018, when Premier Keqiang Li made a report on the work of the government, he also stated that he must vigorously implement the strategy for rejuvenating villages.

The revitalization of the countryside and ecological livability are the keys. A good ecological environment is the greatest advantage and valuable asset in rural areas. The goal of the revitalization of rural ecology is to respect nature, conform to nature, protect nature, promote the accelerating increase of natural capital in rural areas, and realize the unity of the rich people and ecological beauty.

In total, it covers four aspects: coordinating the governance of lakes, grasslands, water and oil, strengthening the comprehensive management of outstanding environmental problems in rural areas, establishing a market-based diversified ecological compensation mechanism, and increasing the supply of agricultural ecological products and services.

Specific details cover all aspects of China's agricultural ecological development.

First of all, the forest and grassland in the mountains and lakes will be treated and protected as a whole system. The system of recuperating and cultivating cultivated prairie, forest, rivers and lakes shall be established, and the marginal 
production capacity of orderly withdrawal from overload shall be classified. Implement major projects for the conservation of biological diversity to effectively prevent the invasion of alien organisms.

In terms of water control, the water sciences have defined areas where rivers, lakes and seas are limited to catching or prohibiting catching, and a sound system for restoration of aquatic ecosystems has been established. Implement the dual control action of the total amount and intensity of water consumption. We will increase efforts to comprehensively reform agricultural water prices. In terms of treating the "lake," we will carry out river and lake system connectivity and rural river and pond dredging and rectification to fully implement the river length system and the lake length system. In terms of governance of the "field", the pilot system for expanding the arable land rotation fallow system was expanded. We will carry out greening operations in the land and promote the comprehensive management of desertification, rocky desertification, and soil erosion. Strengthen the protection and restoration of wetlands and continue to return to farmland and wetlands.

In the area of forest management, the protection system for natural forests has been improved and natural forests have been included in the scope of protection. We will expand the return of farmland to forests and grasslands, returning livestock to grasslands, and establish results to consolidate long-term mechanisms. We will continue to implement key forestry projects such as the construction of the Three North Shelterbelt System. We also will implement precise forest quality improvement projects. In terms of "grass", we continued to implement the grassland ecological protection subsidy policy.

Second, we will carry out green agricultural development activities to reduce input products, clean up production, treatment of agricultural waste, and eco-industry models. Strengthen rural water environmental governance and rural drinking water protection. Expand the comprehensive treatment scope of groundwater overdraft area in North China. To carry out pilot projects for the application of soil pollution control and rehabilitation technologies, including the control and rehabilitation of heavy metal-contaminated farmland. It is forbidden to transfer industrial and urban pollution to agricultural and rural areas. Strengthen the construction of environmental supervision in rural areas and implement the primary responsibility for rural environmental protection at county and township levels.

Third, establish a market-diversified ecological compensation mechanism. In this regard, the reform of China's rural eco-marketization system will mainly include the implementation of a system of agricultural functional areas, encouraging local governments to implement commercial forest abolition systems in key ecological locations, improving the mechanism of horizontal ecological protection and compensatory mechanisms between regions and upstream and downstream river basins, and establishing the Yangtze River The catchment compensation system in key water areas of the river basin and the implementation of the 
ecological work-for-work mechanism.

Finally, increase the supply of agro-ecological products and services. Promote the use of local agricultural resources to promote the industrialization of agriculture. On the one hand, accelerate the development of forest and grassland tourism, tourism in rivers and lakes, ice and snow marine sports, domestication of wild animals and other industries, and actively develop services such as tourism agriculture, recreation, health, and ecological education. On the other hand, a number of characteristic eco-tourism model villages and towns and fine lines were created to create a green eco-friendly rural eco-tourism industrial chain.

\section{The Enlightenment of Marx's Saving Thoughts on the Revitalization of Rural Ecology in China}

\subsection{Pay Attention to the Application of Scientific and Technological Means}

The development of natural sciences and their effective transformation into productive forces are important ways to achieve resource conservation. Therefore, in the process of revitalizing rural ecology, modern science and technology and management methods should be used to transform rural ecological advantages into advantages for the development of ecological economy, provide more and better green ecological products and services, and promote ecological and economic virtuous circles (Wei \& Lu, 2011).

\subsection{Deal with the Relationship between Resources and Excrement}

In the field of comprehensive governance of environmental problems in rural areas, the relationship between resources and excrement should be well handled, dispose of the waste and distinguish between production waste and consumer waste. For the production of excrement, the resources generated by the upstream production as raw materials used for downstream production should be recycled. For consumer waste, on the one hand, it reduces the production of excrement, and on the other hand, it actively explores the agricultural uses of consumer excretion machines, such as alternative fertilizers, livestock and poultry manure treatment, comprehensive utilization of crop stalks, abandoned agricultural film recycling, and pests and diseases.

\subsection{Focus on Economies of Scale and Collaboration}

China's agricultural production has always been characterized by decentralization and block. The rural land and resources are concentrated as much as possible to create economies of scale, which in turn reduces the waste of labor and production resources. For the centralized treatment of forest and forest lands and lakes and grassland systems, the lakes and forests in the mountains and forests are used as a community of life for unified protection and unification. Restoration is an important manifestation of production concentration. At the same 
time, in the process of promoting rural ecological rejuvenation, farmers must be the main and organized, coordinated peasant groups. Marx believes that these peasant groups working in a collaborative manner are the basic prerequisites for resource conservation. The division of labor and cooperation among farmers are promoted in the process of marketization of ecological resources. The system of agricultural functional areas is implemented, transfer payments for key ecological function areas are increased, and incentive and restraint mechanisms linked to ecological protection effectiveness and fund allocation are improved. Local governments are encouraged to implement the commercial forest redemption system in key ecological locations. We will improve the mechanism for compensating horizontal ecological protection between regions and upstream and downstream river basins. We also will explore market-based compensation systems such as the purchase of ecological products and forest carbon sinks, and establish a non-capture compensation system for key waters in the Yangtze River basin.

\subsection{Promote the All-Round Development of Farmers}

It is one of the important goals of China's rural revitalization plan to promote the conversion of necessary labor time for farmers to free time and promote their full-scale development, according to Marx's labor time thinking ( $\mathrm{Zu} \&$ Zhang, 2014).

\section{References}

Liu, F. Y. (2017). Re-Understanding of Labor Product Theory in Socialist Market Economy. Economic Development, 5, 43-46.

Marx (2004). Capital. Peking: People's Press.

Qin, S. S., \& Wang, K. (2014). Marx's Idea of Resource Saving and Its Development in China. Journal of Northeastern University (Social Science Edition), 6, 419-423.

Wang, L. (2006). New Probe into Marx’s Saving Thought. Economist, 9, 29-34.

Wei, C. Y., \& Lu, D. F. (2011). The Current Extravagance and Waste of Local Government and Its Governance. Administration and Law, 11, 11-14.

Zu, L., \& Zhang, B. R. (2014). Japan's Resource-Saving Society and Its Enlightenment. Gansu Theory Journal, 10, 164-167. 